\title{
A Novel Spectrofluorometric Probe for the Determination of Peroxynitrite Anion Scavenging Activity of Biothiols and Amino Acids
}

\author{
Burcu BEKDEŞER, *** Mustafa ÖZyüREK,* Esin AKyüZ,* and Reşat APAK*,**† \\ *Department of Chemistry, Faculty of Engineering, Istanbul University, Avcilar 34320, Istanbul, Turkey \\ **Istanbul University-Application \& Research Center for the Measurement of Food Antioxidants, \\ Istanbul University, Avcilar 34320, Istanbul, Turkey
}

\begin{abstract}
In this study, a novel fluorometric method for the determination of peroxynitrite anion (ONOO-) scavenging (PAS) activity of amino acids and biothiols, which can mostly trap peroxynitrite in vivo, is described. This assay is based on the conversion of a gentisic acid probe to its non-fluorescent oxidation products with $\mathrm{ONOO}^{-}$. The attenuation of the fluorescence intensity (FI) of the probe upon peroxynitrite attack is diminished with antioxidants, the difference in FI being related to the PAS activity of the antioxidants. The $\mathrm{IC}_{50}(50 \%$ inhibitive concentration) values of biothiols, amino acids and tissue homogenates were estimated, in comparison with the reference Pyrogallol Red (PR) bleaching method. PR is the most suitable and frequently used dye to determine PAS activity, but is relatively insensitive. The developed fluorometric assay is highly sensitive to allow determinations of the PAS activity of amino acids.
\end{abstract}

Keywords Peroxynitrite anion, gentisic acid, spectrofluorometric method, Pyrogallol Red bleaching method

(Received March 29, 2016; Accepted August 5, 2016; Published December 10, 2016)

\section{Introduction}

The peroxynitrite anion $\left(\mathrm{ONOO}^{-}\right)$is an effective oxidant known to be crucial in the macrophage killing of various pathogens. ${ }^{1}$ It plays a significant role in neurodegenerative diseases, cardiovascular disorders and inflammation. ${ }^{2}$ The protonated (free acidic) form of $\mathrm{ONOO}^{-}$has a $\mathrm{p} K_{\mathrm{a}}$ of 6.8 , and can decompose to hydroxyl radical $\left({ }^{\circ} \mathrm{OH}\right)$ and nitrogendioxide $\left({ }^{-} \mathrm{NO}_{2}\right) .{ }^{1} \mathrm{ONOO}^{-}$can react with various biomolecules, including thiols and amino acids. ${ }^{3}$ The toxicity of $\mathrm{ONOO}^{-}$is due to its ability to directly oxidize $\left(E_{\mathrm{ONOO}^{-}}=1.40 \mathrm{~V}\right)$ sulfhydryl group of cysteine and glutathione (GSH), ${ }^{4}$ and even the sulfur atom of methionine. ${ }^{5}$ Peroxynitrite attacks on the aromatic ring, mainly giving ortho-, $^{\text {para-hydroxylation and meta-nitration products. }}{ }^{6}$ There are many literature methods for the synthesis of $\mathrm{ONOO}^{-}$ including the oxidation of hydroxylamine, ozonation of azide, photolysis, pulse radiolysis of nitrate, ${ }^{8}$ oxidation of organic nitrate, and the reaction of nitric oxide $\left({ }^{\circ} \mathrm{NO}\right)$ with the superoxide anion radical $\left(\mathrm{O}_{2}{ }^{-}\right) .^{2}$ Only a few chemical groups, such as thiols, iron/sulfur centers and zinc fingers (protein motif) directly react with peroxynitrite. ${ }^{9}$

The most susceptible amino acids to oxidative $\mathrm{ONOO}^{-}$attack are the sulfur-containing (cysteine and methionine) and the aromatic ring-bearing (tryptophan, tyrosine, phenylalanine and histidine) ones. ${ }^{3}$ Low-molecular-weight thiol compounds (like GSH) comprise a variety of effective scavengers that react with ONOO $^{-}$with rate constants ranging from $2 \times 10^{3} \mathrm{M}^{-1} \mathrm{~s}^{-1}$ to

† To whom correspondence should be addressed.

E-mail: rapak@istanbul.edu.tr
$2 \times 10^{8} \mathrm{M}^{-1} \mathrm{~s}^{-1}$, depending on the microenvironment of the thiol. ${ }^{10}$

Tyrosine can be used as the detector molecule for $\mathrm{ONOO}^{-}$. This method also requires multifaceted HPLC equipment for determining the remaining tyrosine and its $\mathrm{ONOO}^{-}$oxidation products (such as 3-nitrotyrosine and 3-hydroxytrosine). ${ }^{11}$ In vivo tyrosine is the primary target for $\mathrm{ONOO}^{-}$damage. Its main reactive group is the $\mathrm{OH}$ group at position 1 , but it has a low PAS activity because of the sizable substituent at position $4 .{ }^{12}$ Dihydrodichlorofluorescein (DCFH) and dihydrorhodamine-123 (DHR) have been used for the determination of PAS activity. ${ }^{13}$ These non-fluorescent probes are converted to fluorescent forms (rhodamine (RH) $\lambda_{\mathrm{ex}}=500 \mathrm{~nm}, \lambda_{\mathrm{em}}=536 \mathrm{~nm}$ and dichlorofluorescein (DCF) $\lambda_{\mathrm{ex}}=502 \mathrm{~nm}, \lambda_{\mathrm{em}}=523 \mathrm{~nm}$ ) with $\mathrm{ONOO}^{-} .^{14}$ DHR can also be oxidized by other reactive oxidants, such as $\mathrm{H}_{2} \mathrm{O}_{2}, \mathrm{HOCl}$, and cytochrome $c$, which may in turn decrease its analytical selectivity for any PAS activity measurement. ${ }^{15}$ The bleaching of dyes (carminic acid, gallein, Evans Blue, Alizarin Red S, etc.) by $\mathrm{ONOO}^{-}$has been frequently used for the determination of antioxidant activity. ${ }^{11}$ Pyrogallol Red (PR) is a frequently used dye for determining PAS activity. ${ }^{16}$ The addition of $\mathrm{ONOO}^{-}$to $\mathrm{PR}$ results in a decrease of absorbance at $454 \mathrm{~nm}$. On the other hand, PR has been shown to bleach with other reactive species, such as $\mathrm{HOCl}, \mathrm{O}_{2}{ }^{--}$, and peroxyl radical (ROO*), which also adversely affects its selectivity as a PAS probe. PR has been used as a $\mathrm{HOCl}$-sensitive probe for determining the antioxidant activity of polyphenols, ${ }^{17-19}$ and also as an indicator for the oxygen radical absorbance capacity (ORAC) assay where its bleaching induced by ROO can be delayed by antioxidants. ${ }^{20}$

Gentisic acid (2,5-dihydroxy benzoic acid), which was used as 
a fluorogenic PAS probe for the first time in this study, has a higher molar fluorescence coefficient $\left(3.65 \times 10^{6} \mathrm{M}^{-1} \mathrm{~cm}^{-1}\right)$ than probes used in absorptimetric $\left(\varepsilon=2.04 \times 10^{4} \mathrm{M}^{-1} \mathrm{~cm}^{-1}\right.$ for $\mathrm{PR}$ probe), and fluorometric $\left(\varepsilon_{500}=5.95 \times 10^{4} \mathrm{M}^{-1} \mathrm{~cm}^{-1}\right.$ for DCF, $\varepsilon_{500}=7.88 \times 10^{4} \mathrm{M}^{-1} \mathrm{~cm}^{-1}$ for RH) assays. Therefore, the new fluorometric method described herein represents a simple and sensitive alternative to the absorptimetric, fluorometric and chromatographic methods existing in the literature. The developed analytical method has been performed on amino acids, biothiols and a tissue homogenate, the scavenging activity measurements of which are important because $\mathrm{ONOO}^{-}$is frequently trapped in vivo by thiols and metalloproteins. ${ }^{21}$ The findings were compared with those of a reference (PR bleaching) method.

\section{Experimental}

\section{Reagents and chemicals}

L-Serine, L-valine, alanine, cysteamine, homocysteine, glycine, L-cystine, pyrogallol red (3,4,5-trihydroxy-9-(2'-sulfophenyl)-6isoxanthone), and manganese(IV) oxide were purchased from Aldrich (Steinheim, Germany); L-glutathione reduced (GSH) and hydroxylamine (50\% by wt.) from Merck (Darmstadt, Germany); 2,5-dihydroxy benzoic acid (gentisic acid), L-cysteine (Cys), L-glutathione oxidized (GSSG), L-methionine, and $\mathrm{N}$-acetyl-L-cysteine (NAC) from Fluka (Buchs, Switzerland). Wistar rats were supplied by the Faculty of Veterinary Medicine of Istanbul University.

\section{Apparatus}

A Varian Cary Eclipse spectrofluorometer and a Varian CARY $100 \mathrm{UV}-$ Vis spectrophotometer (Mulgrave, Victoria, Australia) were used for fluorescence intensity and absorption measurements. Chromatographic separation and detection were performed with a Waters Breeze ${ }^{\mathrm{TM}} 2$ Model HPLC system (Milford, MA, USA) equipped with a 2998 photo-diode array detector. Data acquisition and processing were done using Empower PRO software. Distilled water was supplied from a Simpak1 Synergy purification system (Millipore, USA).

\section{Synthesis of peroxynitrite}

The synthesis of $\mathrm{ONOO}^{-}$was achieved by utilizing the autoxidation of hydroxylamine in an alkaline medium. A mixture of $1.0 \times 10^{-2} \mathrm{M}$ of hydroxylamine, $0.5 \mathrm{M}$ of sodium hydroxide, and $1.0 \times 10^{-3} \mathrm{M}$ of EDTA was stirred strongly in an aerobic medium for about 30 min under oxygen flow, and $1.5 \mathrm{~h}$ without oxygen flow. Manganese (IV) oxide powder was used for removing $\mathrm{H}_{2} \mathrm{O}_{2}$ generated during the reaction. The mixture was filtered through a $0.45-\mu \mathrm{m}$ membrane filter and stored at $-18^{\circ} \mathrm{C}^{13}$ The formation of $\mathrm{ONOO}^{-}$was demonstrable spectrophotometrically at $302 \mathrm{~nm}$, and its concentration was determined by using the molar absorption coefficient $\left(\varepsilon_{302}=\right.$ $1670 \mathrm{M}^{-1} \mathrm{~cm}^{-1}$ ) in accordance with Beer's law. ${ }^{22}$

\section{Preparation of solutions}

Gentisic acid $\left(3.0 \times 10^{-4} \mathrm{M}\right)$ and $\mathrm{Na}_{2} \mathrm{HPO}_{4} / \mathrm{NaH}_{2} \mathrm{PO}_{4} \cdot 2 \mathrm{H}_{2} \mathrm{O}$ buffer solutions, $1.0 \mathrm{M}$, at $\mathrm{pH} 7.4$, were prepared in distilled water. A PR solution $\left(1.33 \times 10^{-4} \mathrm{M}\right)$ was prepared in $1.0 \mathrm{M}$ phosphate buffer. All biothiols and amino acid solutions were freshly prepared in distilled water at suitable concentrations. The mobile-phase constituents for HPLC analysis with gradient elution were pure acetonitrile and $1.0 \%$ acetic acid.

\section{Preparation of tissue homogenate}

The rat tissue homogenates (liver and kidney) were provided by the Animal Facility of the Faculty of Veterinary Medicine of Istanbul University. The tissues were removed after sacrifice by decapitation from rat, washed with a $0.9 \% \mathrm{NaCl}$ solution, weighed $(10 \%, w / v)$ and homogenized in cold $1.15 \% \mathrm{KCl}$ solution. Homogenates were stored at $-80^{\circ} \mathrm{C}$ before being analyzed $^{23}$ and filtered through a $0.45-\mu \mathrm{m}$ membrane filter prior to analysis.

\section{Gentisic acid assay}

The reaction mixture was composed of $1.5 \mathrm{~mL}$ of $1.0 \mathrm{M}$ phosphate buffer ( $\mathrm{pH} 7.4$ ), $0.5 \mathrm{~mL}$ of $3.0 \times 10^{-4} \mathrm{M}$ gentisic acid probe, scavenger solution at an appropriate concentration, and distilled water of dilution to make the final volume $3.5 \mathrm{~mL}$. Finally, $0.5 \mathrm{~mL}$ of $4.5 \times 10^{-4} \mathrm{M} \mathrm{ONOO}^{-}$was added to start the kinetic competition between the scavenger and probe for peroxynitrite. The fluorescence intensity of gentisic acid at $450 \mathrm{~nm}\left(\lambda_{\mathrm{ex}}=267 \mathrm{~nm}\right)$ was measured initially $\left(I_{0}\right)$ and after peroxynitrite attacks with $\left(I_{2}\right)$ or without $\left(I_{1}\right)$ scavenger $\left(I_{0}>I_{2}>\right.$ $\left.I_{1}\right)$. The inhibition ratio $\%$ was calculated by using

$$
\text { Inhibition ratio }(\%)=100\left[\left(I_{2}-I_{1}\right) /\left(I_{0}-I_{1}\right)\right] \text {. }
$$

The $\mathrm{IC}_{50}$ values of the scavengers were found by intersecting the curve of inhibition \% versus the scavenger concentration at $50 \%$ inhibition.

Various tissue homogenates (liver, kidney and heart) were used at appropriate concentrations in the recommended procedure instead of the scavengers. The inhibition percentages of tissue homogenates $(1: 30 \mathrm{v} / \mathrm{v})$ were calculated by using Eq. (1).

In the reaction system only gentisic acid had a fluorescence intensity, whereas neither the scavenger nor scavenger-derived products exhibited a fluorescence intensity at $450 \mathrm{~nm}$. Possible interferences from biological samples were eliminated by diluting sufficiently low amounts of these samples.

\section{PR bleaching assay}

The spectrophotometric reference method ${ }^{24}$ is based on the bleaching of PR dye by $\mathrm{ONOO}^{-}$. The loss of absorbance due to the oxidation of PR was monitored at $540 \mathrm{~nm}\left(\varepsilon=2.04 \times 10^{4}\right.$ $\left.\mathrm{M}^{-1} \mathrm{~cm}^{-1}\right) .^{25}$ The reaction mixture contained $1.5 \mathrm{~mL}$ of $1.33 \times 10^{-4} \mathrm{M}$ PR (in $1.0 \mathrm{M}$ phosphate buffer, $\mathrm{pH} 7.4$ ), a scavenger solution or tissue homogenates $(1: 2 \mathrm{v} / \mathrm{v})$ at an appropriate concentration, and distilled water of dilution to make the final volume $3.5 \mathrm{~mL}$. When $0.5 \mathrm{~mL}$ of $4.5 \times 10^{-4} \mathrm{M}$ $\mathrm{ONOO}^{-}$was added to start the reaction, the absorbance was diminished at $542 \mathrm{~nm}$ due to the oxidation of PR. The inhibition ratio \% was calculated according to the following equation by using absorbances measured initially $\left(A_{0}\right)$ and after peroxynitrite attacks with $\left(A_{2}\right)$ or without $\left(A_{1}\right)$ the scavenger $\left(A_{0}>A_{2}>A_{1}\right)$.

$$
\text { Inhibition ratio }(\%)=100\left[\left(A_{2}-A_{1}\right) /\left(A_{0}-A_{1}\right)\right]
$$

\section{HPLC assay}

HPLC analyses were performed using a Zorbax Eclipse XDB-C18 column $(4.6 \times 250 \mathrm{~mm}, 5 \mu \mathrm{m}$ particle size) (USA). Acetonitrile and $1.0 \%$ acetic acid in bidistilled water (20:80 by vol.) were used for isocratic elution. The detection wavelength and the flow rate were $324 \mathrm{~nm}$ and $1 \mathrm{~mL} \mathrm{~min}^{-1}$, respectively. The calibration curve and linear equation of peak area versus concentration were determined. With the aid of this calibration curve, the gentisic acid concentration remaining in reaction medium was calculated. ${ }^{26}$ 


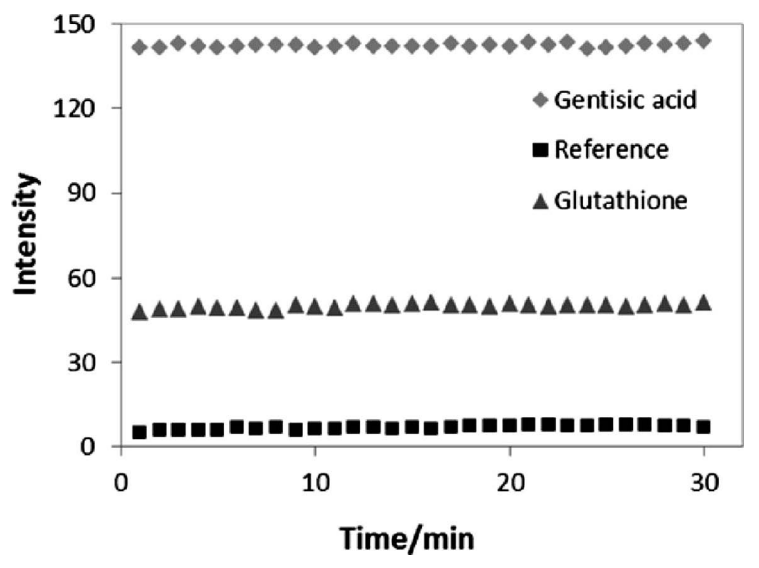

Fig. 1 Fluorescence intensity $v s$. incubation time curves of gentisic acid $(37.5 \mu \mathrm{M})$ alone and gentisic acid subjected to $\mathrm{ONOO}^{-}(56.3 \mu \mathrm{M})$ in the absence (reference) and presence of GSH $(25.0 \mu \mathrm{M})$ in phosphate-buffered (pH 7.4) medium.

\section{Results and Discussion}

The PAS activity of amino acids, biothiols and biological samples were evaluated by using a novel spectrofluorometric method based on the use of a gentisic acid probe. Gentisic acid is a highly fluorescent probe $\left(\lambda_{\mathrm{ex}}=267 \mathrm{~nm}, \lambda_{\mathrm{em}}=450 \mathrm{~nm}\right)$ for which the molar fluorescence coefficient was $3.65 \times 10^{6}$ $\mathrm{M}^{-1} \mathrm{~cm}^{-1}$; the linear concentration range was given as $3.0 \times 10^{-6}-$ $7.5 \times 10^{-5} \mathrm{M}$ (correlation coeffcient of $r=0.9999$ ), within which the relative standard deviation (RSD) was $2.4 \%$. The limit of detection (LOD) and limit of quantification (LOQ) for gentisic acid in the fluorometric assay were found to be 0.81 and $2.71 \mu \mathrm{M}$, respectively. The precision and accuracy of the gentisic acid assay were evaluated by spiking 1:30 diluted liver homogenate with definite concentrations of gentisic acid (22.5, 37.5 and $75 \mu \mathrm{M})$. The relative standard deviations corresponding to these concentrations were found to be $2.81,1.24$ and $0.88 \%$, respectively $(N=3)$. The recovery of the recommended method varied from 101.1 to $96.0 \%$ within increasing concentrations of gentisic acid.

The repeatability of the recommended method for the $\mathrm{IC}_{50}$ values of cysteine $(N=3, \mathrm{RSD} \%)$ was $2.76 \%$.

When the gentisic acid probe was oxidized by $\mathrm{ONOO}^{-}$, the fluorescence intensity of the probe decreased due to the formation of non-fluorescent oxidation products.

Selectivity is a major analytical challenge in the design of new molecular spectroscopic redox probes for reactive species. Since the redox potentials of peroxynitrite at $\mathrm{pH} 7\left(E_{\mathrm{o}}{ }^{\prime}\right)$ for the $\mathrm{ONOO}^{-} / \mathrm{NO}_{2}$ and $\mathrm{ONOO}^{-} / \mathrm{NO}_{2}{ }^{-}$couples have been estimated as 1.4 and $1.2 \mathrm{~V}$, respectively, gentisic acid may be a sufficiently selective redox probe for peroxynitrite because of its high oxidation potential, while ROS having lower oxidation potentials may not oxidize this probe. ${ }^{27}$ The redox potential of the gentisic acid (GA) radical GA $/ \mathrm{GA}$ couple was measured by Joshi et al. ${ }^{28}$ using cyclic voltammetry to be $0.774 \mathrm{~V}$ versus NHE, which is quite high among similar phenolic antioxidants.

Tyrosine is a commonly used probe for determining peroxynitrite scavenging, but it has a surprisingly limited PAS activity. In this test, the $\mathrm{OH}$ group at position 1 is the most reactive group, which is not positively affected by the sizable substutient at position 4. Gentisic acid has an $\mathrm{OH}$ group at positions 2 and 5 , which positively influence each other. ${ }^{12}$

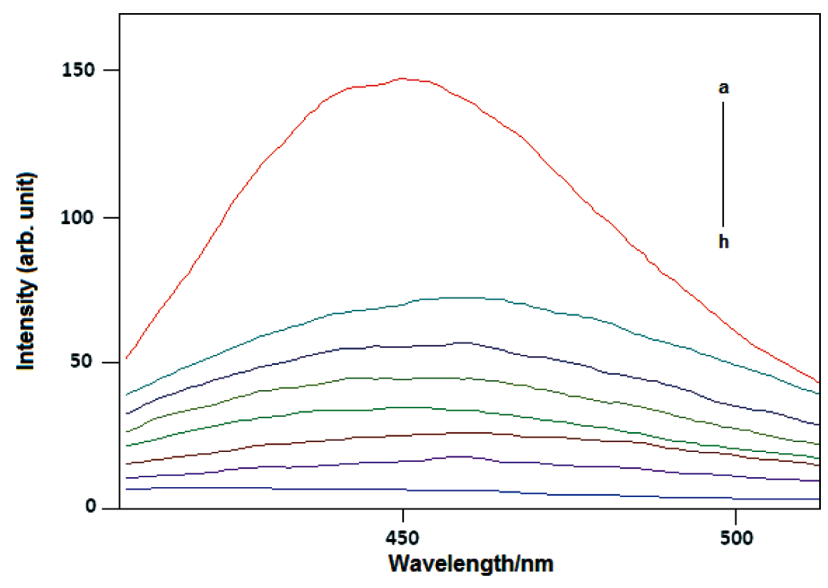

Fig. 2 Fluorescence spectra of gentisic acid alone and gentisic acid subjected to $\mathrm{ONOO}^{-}(56.3 \mu \mathrm{M})$ in the absence and presence of Cys in phosphate-buffered ( $\mathrm{pH}$ 7.4) medium. a, $37.5 \mu \mathrm{M}$ gentisic acid alone; b, $15.0 \mu \mathrm{M}$ Cys; c, $12.5 \mu \mathrm{M}$ Cys; d, $10.0 \mu \mathrm{M}$ Cys; e, $7.5 \mu \mathrm{M}$ Cys; $\mathrm{f}$ $5.0 \mu \mathrm{M}$ Cys; g, $2.5 \mu \mathrm{M}$ Cys; h, reference.

Peroxynitrous acid $(\mathrm{ONOOH})$ is rapidly generated by the reaction of $\mathrm{H}_{2} \mathrm{O}_{2}$ with $\mathrm{HNO}_{2}$ in an acid medium, but the compound is unstable $\left(t_{1 / 2}\right.$ is a few seconds at $\left.0^{\circ} \mathrm{C}\right) .{ }^{29}$ Therefore, a quenched-flow reactor should be used for generating relatively stable $\mathrm{ONOO}^{-}$by this method. ${ }^{13}$ The reaction of $\mathrm{H}_{2} \mathrm{O}_{2}$ with alkyl nitrites in alkaline media is another commonly used method, but the $\mathrm{ONOO}^{-}$solution contains an equimolar amount of alcohol that can be oxidized with $\mathrm{ONOO}^{-} .^{29}$ We generated $\mathrm{ONOO}^{-}$by the autoxidation of hydroxylamine in an alkaline solution. ${ }^{13}$ The advantage of this procedure is to have $\mathrm{ONOO}^{-}$ as the major product. ${ }^{30}$ The formation of $\mathrm{ONOO}^{-}$was observed by following a new absorption band appearing at $302 \mathrm{~nm}$. Moreover, the accompanying species (such as hydroxylamine, $\mathrm{NO}_{3}^{-}, \mathrm{NO}_{2}^{-}$, and $\mathrm{H}_{2} \mathrm{O}_{2}$ ), taking part in $\mathrm{ONOO}^{-}$synthesis did not cause a fluorescence decrease of the gentisic acid probe (data not shown).

The diminution of the fluorescence intensity of the gentisic acid probe was followed as a function of time. While the fluorescence intensity of gentisic acid (alone) remained constant within the $0-30$ min time interval, it decreased and leveled off in a few seconds (showing the rapidity of the assay) in the presence and absence of GSH (Fig. 1). A greater decrease of the initial fluorescence intensity was observed when scavenger (GSH) was absent because of the maximal conversion of the gentisic acid probe to non-fluorescent oxidation products.

The fluorescence spectra of gentisic acid, obtained in the presence and absence of a scavenger (Cys), are shown in Fig. 2. When the gentisic acid probe was subjected to $\mathrm{ONOO}^{-}$, its initial fluorescence intensity (a) decreased. The decline of the fluorescence intensity was maximum in the absence of the scavenger (reference (h)). It can be observed that increasing the scavenger concentration from 2.5 to $15 \mu \mathrm{M}(\mathrm{g}-\mathrm{b})$ increased the fluorescence intensity because of competition between the probe and the scavenger. This increment is proportional to the scavenging activity of the antioxidant, as can be seen from the significant rise of the peak heights of gentisic acid subjected to peroxynitrite attack in the presence of scavengers, such as Cys (Fig. 2).

There were slight red-shifts in the fluorescence spectra of the probe subjected to peroxynitrite attacks with increasing concentrations of thiol (Fig. 2). The rate constant for 


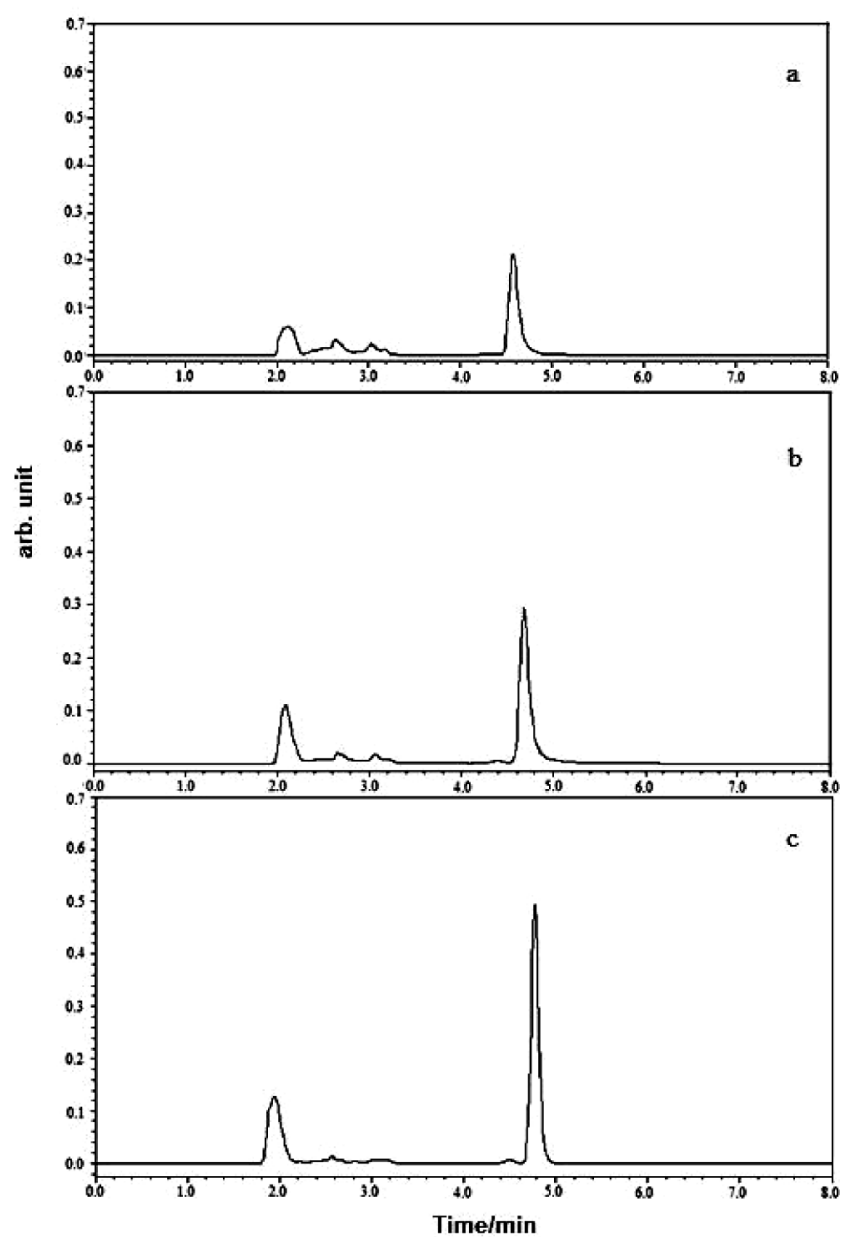

Fig. 3 HPLC chromatograms for gentisic acid probe ( $\left.t_{\mathrm{R}}: 4.99 \mathrm{~min}\right)$. a, Reference $(1.5 \mathrm{~mL}$ phosphate buffer $+0.5 \mathrm{~mL}$ of $0.9 \mathrm{mM}$ gentisic acid $+1.2 \mathrm{~mL}$ water $+0.8 \mathrm{~mL}$ of $\left.0.67 \mathrm{mM} \mathrm{ONOO}^{-}\right) ; \mathrm{b}, 1.5 \mathrm{~mL}$ phosphate buffer $+0.5 \mathrm{~mL}$ of $0.9 \mathrm{mM}$ gentisic acid $+x=0.1 \mathrm{~mL}$ of $10 \mathrm{mM} \mathrm{GSH}+(1.2-x) \mathrm{mL}$ water $+0.8 \mathrm{~mL}$ of $0.67 \mathrm{mM} \mathrm{ONOO}^{-} ; \mathrm{c}$, $x=0.5 \mathrm{~mL}$ of $10 \mathrm{mM} \mathrm{GSH}$.

peroxynitrite scavenging of the probe (i.e. gentisic acid) is presumably much lower than that of thiols, implying that $\mathrm{ONOO}^{-}$should be scavenged by R-SH much faster than it would react with the probe. Inspection of the rate constants of peroxynitrite scavenging reactions of thiols and hydroxybenzoates shows that they may be comparable for slow-reacting thiols, but not for fast-reactors. For example, the nitration of $p$-hydroxyphenylacetic acid (an analogic molecule similar to the probe) belongs to faster peroxynitrite reactions; its rate constant is $5 \times 10^{3} \mathrm{M}^{-1} \mathrm{~s}^{-1}$ at physiological $\mathrm{pH} .{ }^{31}$ On the other hand, the scavenging of peroxynitrite by hydroxycinnamic acids occurs by two possible mechanisms: preferential nitration for monophenolates and electron donation for the catecholates, ${ }^{32}$ meaning that both nitration and hydroxylation products may be formed simultaneously ${ }^{33}$ and aromatic hydroxylation products may be further oxidized to electrophilic quinones at low conversion ratios. Once the quinone is formed, even at low concentrations, it may add up a nucleophilic - $\mathrm{SH}$ compound relatively easily. Rusin et al. ${ }^{34}$ showed that when cysteine or homocysteine reacts with the carbonyl moieties of xanthene dyes, absorptiometric or fluorometric maxima are red-shifted as a result of $-\mathrm{SH}$ addition reactions, arising from intramolecular charge transfer (ICT) between electron-rich and electron-
Table 1 PAS activity of biothiols and amino acids measured by the fluorometric method in comparison to the spectrophotometric method ( $\mathrm{IC}_{50}$ values were calculated with respect to Eqs. (1) and (2), $N=4$ or 5 data points)

\begin{tabular}{lcc}
\hline \multicolumn{1}{c}{$\begin{array}{c}\text { ONOO }^{-} \\
\text {scavengers }\end{array}$} & $\begin{array}{c}\text { Gentisic acid } \\
\text { assay/M }\end{array}$ & $\begin{array}{c}\text { PR bleaching } \\
\text { assay/M }\end{array}$ \\
\hline Glutathione (GSH) & $4.00 \times 10^{-5}$ & $3.02 \times 10^{-3}$ \\
$N$-acetyl-cysteine (NAC) & $7.83 \times 10^{-5}$ & $8.30 \times 10^{-3}$ \\
Cysteine & $1.45 \times 10^{-5}$ & $2.20 \times 10^{-3}$ \\
Homocysteine & $4.38 \times 10^{-5}$ & $5.70 \times 10^{-3}$ \\
Cysteamine & $8.90 \times 10^{-6}$ & $2.00 \times 10^{-3}$ \\
Methionine & $3.05 \times 10^{-4}$ & $3.50 \times 10^{-2}$ \\
GSSG & $6.70 \times 10^{-4}$ & $9.58 \times 10^{-2}$ \\
Cystine & $2.42 \times 10^{-4}$ & $7.00 \times 10^{-2}$ \\
Homocystine & $3.60 \times 10^{-4}$ & - \\
Glycine & $6.63 \times 10^{-2}$ & - \\
Valine & $6.05 \times 10^{-2}$ & - \\
Serine & $5.60 \times 10^{-2}$ & - \\
Alanine & $11.12 \times 10^{-2}$ & - \\
\hline
\end{tabular}

deficient groups ${ }^{35}$ within the adduct molecule. In the case when phenols are oxidized faster than thiols, the Michael addition of nucleophilic thiols to quinones (i.e. emerging as the oxidation products of phenols) may rapidly produce new products (thiolquinone adducts), depending on the nature, number and position of substituents on the quinone. ${ }^{36}$ Although the major reaction occurring with thiols is $\mathrm{ONOO}^{-}$scavenging, leaving more gentisic acid intact and maintaining more fluorescence, the minor side reactions may produce slightly red-shifted adducts manifesting themselves only with increased thiol concentration. However, these minor side-reactions do not adversely affect the quantitative ability of the proposed peroxynitrite scavenging assay.

The chromatograms used for gentisic acid determinations (in a reaction medium containing peroxynitrite and scavenger) are shown in Fig. 3. The remaining amount of gentisic acid probe in the reaction mixture was comparatively determined by fluorometric and HPLC methods using the linear calibration equation $\left(y=4.74 \times 10^{9} C_{\text {gentisic acid }}+5.74 \times 10^{4}\right)$. The results found with both assays were in compliance with each other with a tolerable error, and correctly reflected the relative decrease in probe conversion into oxidation products in the presence of GSH.

In the absence of a scavenger (reference), the concentrations of gentisic acid according to fluorometric and HPLC methods were found to be $3.38 \times 10^{-4}$ and $3.39 \times 10^{-4} \mathrm{M}$, respectively $\left([\text { gentisic acid }]_{\text {initial }}=1.125 \times 10^{-3} \mathrm{M}\right)$.

The concentrations of gentisic acid probe in the presence of $0.1 \mathrm{~mL}$ GSH were found to be $4.43 \times 10^{-4}$ and $4.68 \times 10^{-4} \mathrm{M}$ with respect to the fluorometric and HPLC methods, whereas with $0.5 \mathrm{~mL}$ GSH these concentrations increased to $6.30 \times 10^{-4}$ and $6.13 \times 10^{-4} \mathrm{M}$, respectively. The results of the fluorometric assay correlated well $(r=0.9919)$ with those of the HPLC method $(N=3)$.

\section{Comparison of the findings of the gentisic acid and PR bleaching assays}

Pyrogallol Red (PR) is a colored reagent, which is readily oxidized by $\mathrm{ONOO}^{-}, \mathrm{H}_{2} \mathrm{O}_{2}, \mathrm{O}_{2}{ }^{-}, \mathrm{HOCl}$ and $\mathrm{ROO}^{-}{ }^{17-19}$ These oxidations can be monitored by changes in the absorption band at $540 \mathrm{~nm}$.

PAS activity ( $\mathrm{IC}_{50}$ value) of biothiols and amino acids measured by the fluorometric and PR bleaching methods are 


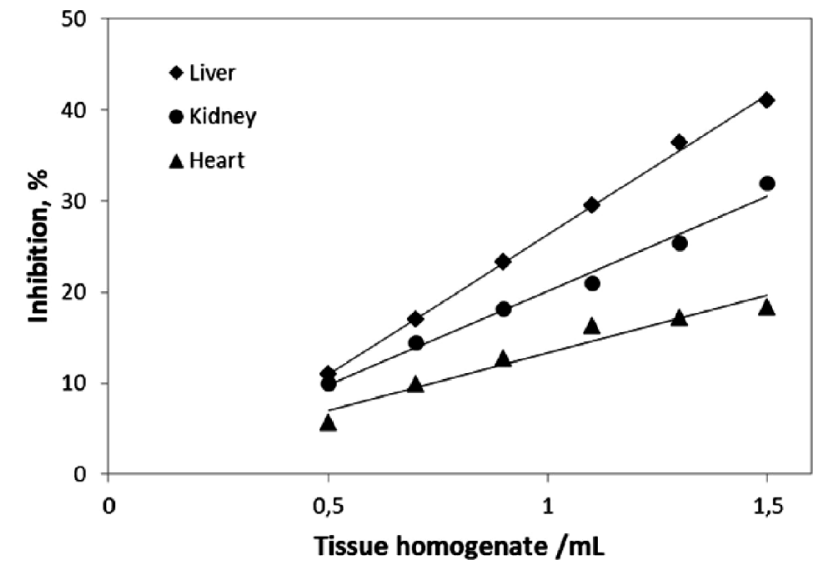

Fig. 4 Inhibition $\%$ of tissue homogenates as a function of homogenate volume using gentisic acid assay (1:30 diluted liver $(\diamond)$ kidney (O) and heart ( $\boldsymbol{(})$ homogenate).

listed in Table 1. It demonstrates that the $\mathrm{IC}_{50}$ values found with the fluorometric assay were lower than those found with the PR bleaching assay. Biothiols were shown by the fluorometric gentisic acid assay to be more effective scavengers than amino acids, whose $\mathrm{IC}_{50}$ values cannot be calculated by the PR bleaching assay because of insufficient sensitivity.

The Spearman's rank correlation test was employed for comparative $\mathrm{IC}_{50}$ values found with the gentisic acid assay and the PR bleaching assay. The interrater Spearman's rank correlation (consisting of eight peroxynitrite scavengers) was high and statistically significant $(r=0.9762, p<0.001)$.

The molar fluorescence coefficient of the gentisic acid probe $\left(\varepsilon_{450 \mathrm{~nm}}=3.65 \times 10^{6} \mathrm{M}^{-1} \mathrm{~cm}^{-1}\right)$ is much greater than the molar absorption coefficient $\left(\varepsilon_{540 \mathrm{~nm}}=2.04 \times 10^{4} \mathrm{M}^{-1} \mathrm{~cm}^{-1}\right)$ of the PR probe (i.e by a factor of $10^{2}$ ). When Table 1 is examined, the $\mathrm{IC}_{50}$ values calculated with the two assays reflect this hundred-fold difference.

Even though PR is the best among dyes (carminic acid, gallein, Evans Blue, Alizarin Red S etc.) which can be used for determining the PAS activity, ${ }^{11}$ its sensitivity is low because it is based on measurements of the absorbance. For this reason we used a novel fluorometric probe in order to improve the sensitivity. In general, fluorometric probes are more sensitive than absorptiometric ones. The highest PAS activities in the gentisic acid assay were observed for cysteamine $>$ cysteine $>$ GSH > homocysteine $>$ NAC > cystine > methionine > homocystine $>$ GSSG in this order in accordance with PR bleaching assay.

L-cysteine was previously reported as an efficient $\mathrm{ONOO}^{-}$ scavenger $\left(\mathrm{IC}_{50}=25 \mu \mathrm{M}\right)$ through competitive oxidation of free sulfhydryls. ${ }^{37}$ The peroxynitrite-mediated oxidation of biothiols can occur through one-electron oxidation reactions. ${ }^{38}$ Peroxynitrite possibly oxidizes a variety of thiols by forming the corresponding thiyl anion radicals as intermediary products. ${ }^{39}$

\section{$\mathrm{ONOO}^{-}$scavenging activity of some tissue homogenates}

Preliminary experiments for deciding the optimal dilution ratio of tissue homogenates showed that the initial intensity of gentisic acid probe $(I=139)$ was not affected in the presence of 1:30 diluted liver homogenate $(I=137)$, which had a negligible intensity $(I=8)$ by itself. On the other hand, the intensity of gentisic acid was slightly diminished $(I=120)$ when 1:5 diluted liver homogenate was used as the scavenger. The liver homogenate with 1:5 dilution exhibited a slight fluorescence

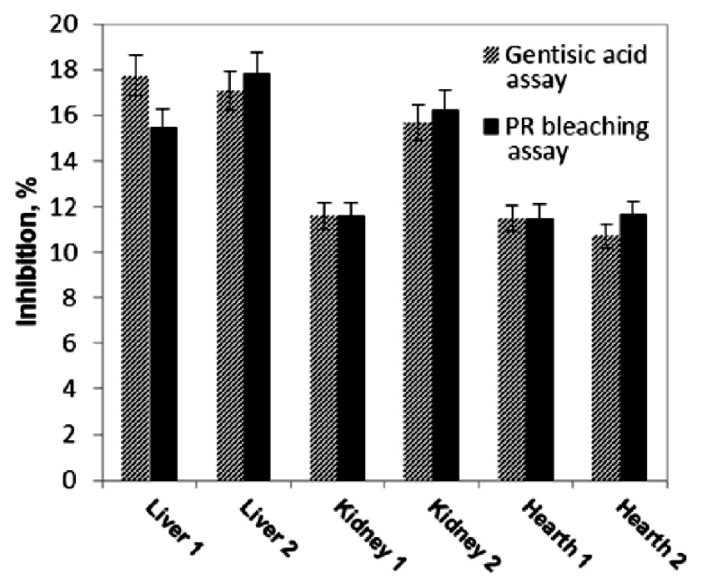

Fig. 5 Peroxynitrite scavenging activity of some tissue homogenates calculated with the gentisic acid assay in comparison to the PR bleaching assay.

intensity $(I=22)$ at $450 \mathrm{~nm}$ when excited at $267 \mathrm{~nm}$ (figure not shown). These findings show that the interference effect of tissue homogenates on gentisic acid could be eliminated by increasing the dilution ratio at the optimal levels (i.e. 1:30), but over dilution could prevent the observation of peroxynitrite scavenging. The PAS activity of heart, liver and kidney homogenates as percent inhibition versus homogenate volume is shown in Fig. 4. A linear relationship was observed between percentage inhibition and the homogenate volume $(0.5-1.5$ $\mathrm{mL}$ ). The $\mathrm{ONOO}^{-}$scavenging activity values evaluated with the gentisic acid assay and reference PR bleaching assay are comparatively displayed in a bar diagram (Fig. 5). The PAS activity of liver tissue homogenate was found to be higher than that of kidney and heart homogenates with respect to both methods, probably because liver is the central organ for enzymatic and non-enzymatic antioxidative defenses of detoxification in the organism. It was shown by Youdim and Deans $^{40}$ in an investigation following the changes with age in the liver, kidney and heart total antioxidant status (TAS, as mM trolox equivalents, measured with the ABTS method) that the concerned TAS order was liver $>$ kidney $>$ heart, in accordance with our results. The smallest content of antioxidants was in the heart, probably because of the extreme aerobic conditions under which the heart operates (i.e., molecular oxygen and related metabolic ROS should consume antioxidants acting as chemical reductants). The low antioxidant reserve of the heart averages about $1 \%$ of that expressed by the liver. ${ }^{41}$ For example, the hypoxic preconditioning of rat heart was shown to better maintain the antioxidative components of ascorbate and thiols in the antioxidant reserve. ${ }^{42}$

\section{Conclusions}

A spectrofluorometric analytical method based on the gentisic acid probe was developed for determining the peroxynitrite anion scavenging activity of biothiols and amino acids. Gentisic acid is a more sensitive and sufficiently selective redox probe for peroxynitrite than the Pyrogallol Red probe. The molar emission/absorption coefficients of the two probes differ by two orders of magnitude, revealing that the recommended method is much more sensitive. The $\mathrm{IC}_{50}$ values found with the gentisic acid assay are in accordance with the PR bleaching assay in 
terms of the rank correlation. These results demonstrate that biothiols are better peroxynitrite scavengers than amino acids, and that the PAS activity of liver tissue homogenate is higher than those of kidney and heart homogenates.

\section{Acknowledgements}

The authors would like to express their gratitude to Istanbul University-Application \& Research Center for the Measurement of Food Antioxidants (Istanbul Universitesi Gida Antioksidanlari Olcumu Uygulama ve Arastirma Merkezi). The authors also extend their gratitude to Scientific Research Projects Coordination Unit of Istanbul University for financial support (NP-20789).

\section{References}

1. T. D. Oury, L. Tatro, A. J. Ghio, and C. A. Piantadosi, Free Radic. Res., 1995, 23, 537.

2. C. Ducrocq, B. Blanchard, B. Pignatelli, and H. Ohshima, Cell. Mol. Life Sci., 1999, 55, 1068

3. B. Alvarez and R. Radi, Amino Acids, 2003, 25, 295.

4. L. Zhu, C. Gunn, and J. S. Beckman, Arch. Biochem. Biophys., 1992, 298, 452.

5. L. B. Valdez, S. Alvarez, S. L. Arnaiz, F. Schöpfer, M. C. Carreras, J. J. Poderoso, and A. Boveris, Free Radic. Biol. Med., 2000, 29, 349.

6. E. Halfpenny and P. L. Robinson, J. Chem. Soc. A, 1952, 939.

7. W. A. Pryor, R. Cueto, X. Jin, W. H. Koppenol, M Nguschwemlein, and G. L. Squadrito, Free Radic. Biol. Med., 1995, 18, 75.

8. T. Logager and K. Sehested, J. Phys. Chem., 1993, 97, 6664.

9. I. Sadowska-Bartosz, R. Adamczyk, and G. Bartosz, Food Chem., 2014, 164, 228.

10. J. P. Crow, Free Radic. Biol. Med., 2000, 28, 1487.

11. G. Gilbert, A. Balavoine, and Y. V. Geletii, Nitric Oxide, 1999, $3,40$.

12. C. G. M. Heijnen, G. R. M. M. Haenen, J. A. J. M. Vekemans, and A. Bast, Environ. Toxicol. Pharmacol. 2001, 10, 199.

13. X.-F. Yang, X.-Q. Guo, and Y.-B. Zhao, Talanta, 2002, 57, 883.

14. J. Glebska and W. H. Koppenol, Free Radic. Biol. Med., 2003, 35, 676 .

15. A. Gomes, E. Fernandes, and J. L. F. C. Lima, J. Biochem. Biophys. Methods, 2005, 65, 45.

16. V. B. Bhat and K. M. Madyastha, Biochem. Biophys. Res. Commun., 2001, 285, 262.

17. F. Pérez-Cruz, C. Cortés, E. Atala, P. Bohle, F. Valenzuela,
C. Olea-Azar, H. Speisky, A. Aspée, E. Lissi, C. LópezAlarcón, and R. Bridi, Molecules, 2013, 18, 1638.

18. C. López-Alarcón and E. Lissi, Free Radic. Res., 2006, 40, 979.

19. M. Faundez, M. Rojas, P. Bohle, C. Reyes, M. E. Letelier, M. E. Aliaga, H. Speisky, E. Lissi, and C. Lopez-Alarcon, Anal. Biochem., 2011, 419, 284.

20. A. Robaszkiewicz and G. Bartosz, Biochem. Biophys. Res. Commun., 2009, 390, 659.

21. W. A. Pryor, Am. J. Physiol., 1995, 268, 699.

22. M. N. Hughesi and H. G. Nicklin, J. Chem. Soc. A, 1968 450.

23. M. Alía, C. Horcajo, L. Bravo, and L. Goya, Nutr. Res., 2003, 23, 1251.

24. V. B. Bhat and K. M. Madyastha, Biochem. Biophys. Res. Commun., 2001, 285, 262.

25. R. G. Brannan and E. Mah, Meat Science, 2007, 77, 540

26. J.-H. Liu and P. C. Smith, J. Chromatogr. B, 1996, 675, 61 .

27. W. H. Koppenol, J. J. Moreno, W. A. Pryor, H. Ischiropoulos, and J. S. Beckman, Chem. Res. Toxicol., 1992, 5, 834.

28. R. Joshi, R. Gangabhagirathi, S. Venu, S. Adhikari, and T. Mukherjee, Free Radic. Res., 2012, 46, 11.

29. V. L. Lobachev and E. S. Rudakov, Russ. Chem. Rev., 2006 75,375 .

30. M. N. Hughes and H. G. Nicklin, J. Chem. Soc. A, 1971, 164.

31. G. Bartosz, Acta Biochim. Pol., 1996, 43, 645.

32. A. S. Pannala, R. Razao, B. Halliwell, S. Singh, and C. A. Rice-Evans, Free Radic. Biol. Med., 1998, 24, 594.

33. M. S. Ramezanian, S. Padmaja, and W. H. Koppenol, Chem. Res. Toxicol., 1996, 9, 232.

34. O. Rusin, N. N. St. Luce, R. A. Agbaria, J. O. Escobedo, S Jiang, I. M. Warner, F. B. Dawan, K. Lian, and R. M. Strongin, J. Am. Chem. Soc., 2004, 126, 438.

35. W. Lin, L. Long, L. Yuan, Z. Cao, B. Chen, and W. Tan, Org. Lett., 2008, 10, 5577.

36. A. Bast and G. R. M. M. Haenen, Environ. Toxicol. Pharm., 2002, 11, 251

37. N. W. Kooy, J. A. Royall, and H. Ischlropoulos, Free Radic Res., 1997, 27, 245.

38. C. Quijano, B. Alvarez, R. M. Gatti, O. Augusto, and R. Radi, Biochem. J., 1997, 322, 167.

39. H. Karoui, N. Hogg, C. Fréjaville, P. Tordo, and B. Kalyanaraman, J. Biol. Chem., 1996, 271, 6000.

40. K. A. Youdim and S. G. Deans, Mech. Ageing Dev., 1999, 109, 163.

41. A. Frustaci, E. Sabbioni, S. Fortaner, M. Farina, R. del Torchio, M. Tafani, E. Morgante, M. R. Ciriolo, M. A. Russo, and C. Chimenti, Eur. J. Heart Fail., 2012, 14, 202.

42. D. T. Engelman, M. Watanabe, R. M. Engelman, J. A. Rousou, E. Kisin, V. E. Kagan, N. Maulik, and D. K. Das, Cardiovasc. Res., 1995, 29, 133. 